\title{
Anaemia prevalence and associated sociodemographic and dietary factors among Palestinian adolescents in the West Bank
}

\author{
N. Mikki, ${ }^{1,2}$ H.F. Abdul-Rahim, ${ }^{2,3}$ H. Stigum ${ }^{1,4}$ and G. Holmboe-Ottesen ${ }^{7}$
}

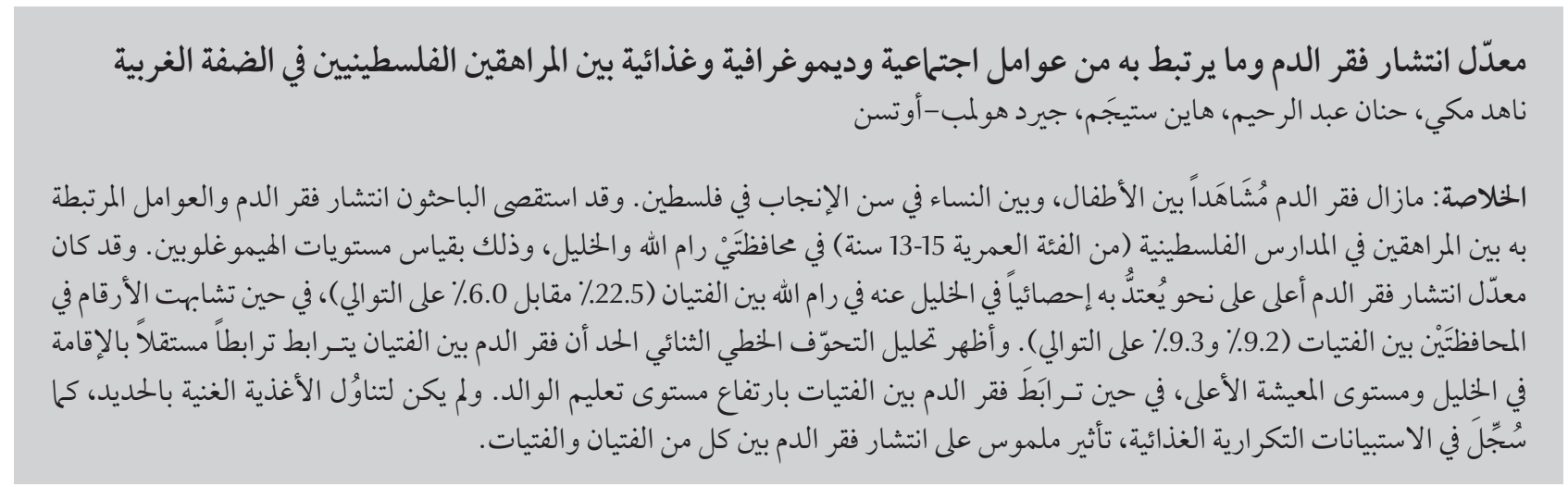

ABSTRACT Anaemia still persists among children and women of childbearing age in Palestine. We investigated the prevalence of anaemia and associated factors among Palestinian school adolescents (aged 13-15 years) in Ramallah and Hebron governorates. Haemoglobin levels were measured to assess the prevalence of anaemia. The prevalence of anaemia was significantly higher in Hebron than in Ramallah among boys (22.5\% versus $6.0 \%$ respectively), while among girls the figures were similar (9.2\% and 9.3\% respectively). Linear binomial regression analysis showed that among boys, anaemia was independently associated with residence in Hebron and higher standard of living, while among girls, anaemia was associated with higher father's education. Consumption of iron-rich foods, as recorded in food frequency questionnaires, had no significant effects on anaemia prevalence in both boys and girls.

Prévalence de l'anémie et facteurs sociodémographiques et alimentaires associés chez des adolescents en Cisjordanie RÉSUMÉ L'anémie reste une affection persistante chez les enfants et les femmes en âge de procréer en Palestine. Nous avons étudié la prévalence de l'anémie et des facteurs associés chez les adolescents fréquentant des écoles palestiniennes (âgés de 13 à 15 ans) dans les gouvernorats de Ramallah et d'Hébron. Les taux d'hémoglobine ont été mesurés pour évaluer la prévalence de l'anémie. La prévalence de l'anémie était significativement supérieure à Hébron par rapport à Ramallah chez les garçons (22,5 \% par rapport à 6,0 \%, respectivement), alors que chez les filles, les chiffres étaient similaires (9,2\% et 9,3\%, respectivement). L'analyse de régression linéaire de type binomial a révélé que chez les garçons, l'anémie était indépendamment associée au lieu de résidence à Hébron et à un niveau de vie élevé, alors que chez les filles, l'anémie était associée à un niveau d'instruction élevé du père. La consommation d'aliments riches en fer, telle qu'indiquée dans les questionnaires de fréquence de consommation alimentaire, n'avait d'effet important sur la prévalence de l'anémie ni chez les garçons, ni chez les filles.

${ }^{7}$ Section of Preventive Medicine and Epidemiology, Institute of General Practice and Community Medicine, University of Oslo, Oslo, Norway (Correspondence to N. Mikki: nahedmikki@yahoo.com).

2Institute of Community and Public Health, Birzeit University, Ramallah, Palestine.

${ }^{3}$ Social and Economic Survey Research Institute and Department of International Affairs, University of Qatar, Doha, Qatar.

${ }^{4}$ Norwegian Institute of Public Health, Oslo, Norway.

Received: 15/08/09; accepted: 13/09/09 


\section{Introduction}

Anaemia is one of the most common nutritional problems in many parts of theworld, especially in developing countries [1]. A major health consequence of anaemia includes impaired cognitive and physical development in children $[1,2]$. Low intake of iron-rich food is a risk factor for stunting [3]. Other consequences include reduced work capacity in adults as well as increased risk of maternal and child mortality and morbidity and poor pregnancy outcome [2]. The main cause of anaemia is iron deficiency due to inadequate intake of bioavailable iron from the diet [4]. Other causes include infectious diseases, deficiencies of micronutrients such as folate, vitamin B12, inherited conditions such as thalassaemia [2] and environmental pollutants such as lead [5].

In Palestine, anaemia still persists among children and women of childbearing age $[6,7]$. However, studies measuring anaemia prevalence among Palestinian adolescents are rare. The present cross-sectional study aimed to assess the prevalence of anaemia and associated sociodemographic and dietary factors among Palestinian adolescent students (aged 13-15 years) in Ramallah and Hebron governorates in Palestine.

\section{Methods}

\section{Study population and sample}

The study was a school-based crosssectional survey conducted in Ramallah and Hebron governorates between March and May 2005. Ramallah governorate (279 730 inhabitants in 2007) is located in the middle of the West Bank [8], while Hebron governorate (552 164 inhabitants) is located in the south [8]. The sample was selected to be representative of the 8 th and 9 th grade students in these 2 governorates, using stratified single-stage probability proportional-to-size sampling within each governorate in which the class was the primary sampling unit. A list of year 2004-05 students in these 2 grades was provided by the Palestinian Ministry of Education and Higher Education. A total of 65 classes were selected: 34 in Ramallah and 31 in Hebron. All students in the chosen classes were invited to participate in the study.

\section{Questionnaire}

Self-administered questionnaires were used to collect information from students and parents about sociodemographic factors and food intake. The questionnaires were piloted and adjusted before the survey. The students' questionnaire was tested for reliability (1-week test-retest) on a different sample of 115 students in the same age group.

\section{Sociodemographic factors}

The educational level of the parents was classified as: low (illiterate or less than secondary school education); medium (secondary school education); or high (college or university education). Residence was classified as urban or rural based on the Palestinian Central Bureau of Statistics (PCBS) classification [9]. A household standard of living index was devised based on household possessions. A score of 1 was given to ownership of each of the following items: central heating, family car, family mobile phone, personal mobile phone, indoor bathroom, water pipes, refrigerator, automatic washing machine, colour television, satellite television, video, computer, dishwasher, microwave, vacuum cleaner and Internet connection. The scores were summed to give a standard of living score range of 0-16. Three categories were constructed: "low", $\leq$ 6; "medium", 7-10 and "high", 11-16. The 1-week test-retest of the ownership of these amenities showed consistent answers ranging between $86.1 \%$ and $99.1 \%$.

Onset of puberty was assessed by the question "Have you had your first period?" for girls and "Have you noticed deepening of your voice?" for boys. The 1-week test-retest for the onset of puberty showed consistent answers of $92.3 \%$ in boys and $95.2 \%$ in girls.

\section{Food frequency list}

The student questionnaire had a food frequency list of 42 items without portion sizes except for bread. The food and beverage questions were: "How often do you drink/eat the following items?" The response categories in the food frequency list were converted to frequencies in times/week (in parentheses) and these response categories were: > 4 times/day (35.0), 3-4 times/ day (24.5), 1-2 times/day (10.5), 4-6 times/week (5.0), 2-3 times/week (2.5), once/week (1.0), 2-3 times/ month (0.5), and seldom/never (0).

The following iron-rich foods and tea scores were included: animal food score [meat from beef, lamb, chicken, liver, kidney, shawerma (local dish made from beef or lamb or chicken), sausage, hamburger, cold cuts and eggs]; legumes score [chickpeas, falafel (fried broad beans), lentils, broad beans, beans and peas]; green leafy vegetables scores: molokheya (Jew's mallow) and spinach, mallow, chicory and garden rocket; tea score (black tea). The scores for the 4 food groups were constructed by the sum of the recoded responses (to weekly frequency intakes) of items included in each score, divided by the number of items. The daily quantity of taboun bread (traditional wholewheat bread) consumed was also included.

The 1 week test-retest reliability of the scores among 115 participants showed a Spearman correlation with a range of $0.55-0.65$.

\section{Blood analysis \& anthropometric measurements}

Haemoglobin ( $\mathrm{Hb}$ ) assays were conducted on capillary finger-prick blood samples using a haemoglobin photometer (HemoCue B). Haemoglobin 
photometers were calibrated daily using dry standard and liquid controls. Anaemia was defined according to World Health Organization (WHO) cut-offs as $\mathrm{Hb}$ level $<12.0 \mathrm{~g} / \mathrm{dL}$ for girls and $<$ $12.0 \mathrm{~g} / \mathrm{dL}$ for boys under 15 years old or $13 \mathrm{~g} / \mathrm{dL}$ for boys aged 15 years and over . Mild anaemia was defined as Hb levels between $9.0 \mathrm{~g} / \mathrm{dL}$ and the cut-off points, moderate anaemia was $\mathrm{Hb} 7.0-8.9 \mathrm{~g} /$ $\mathrm{dL}$ and severe anaemia was $\mathrm{Hb}<7.0 \mathrm{~g} /$ $\mathrm{dL}[1]$.

Students' weight in light clothes without shoes was measured to the nearest $0.1 \mathrm{~kg}$ using a portable scale (Seca 780/783), and height without shoes was measured to the nearest 0.1 $\mathrm{cm}$ using a portable stadiometer (Seca 220). Underweight was defined according to age- and sex-specific body mass index $(\mathrm{BMI})\left(\mathrm{kg} / \mathrm{m}^{2}\right)$ as $<5$ th percentile of the 2000 Centers for Disease Control Prevention (CDC) reference [10]. Stunting was defined according to the age and sex height percentiles as < 3rd percentile [10].

\section{Ethical considerations}

Informed consent was obtained from parents, students and school principals. The study was approved by the Palestinian Ministry of Education and Higher Education, the Office of Education of the United Nations Relief and Works Agency for Palestine Refugees in the Near East and the Regional Ethical Committee of Norway.

\section{Statistical analysis}

Statistical analysis was performed using Stata, version 10.1, to adjust for cluster sampling. Chi-squared tests were used to compare frequencies and $t$-tests to compare means. The sample was weighed according to the sample and population sizes in each governorate (inverse of sampling probability).

A linear binomial regression model was used. We were interested in the effect of both the sociodemographic variables on anaemia and in the effect of nutritional variables adjusted for sociodemographic variables. Hence 2 models were constructed. In model 1 we adjusted for sociodemographic variables and in model 2 we added the nutritional variables to the sociodemographic variables. For model 2, we only reported on the added variables. The modelling process was carried out separately for boys and girls. We tested for all plausible interactions between the variables in the model and checked the linear effects of the covariates. We looked for points of high influence and for predicted values outside 0 and 1 as this model does not constrict the risk of anaemia between these 2 values.

\section{Results}

Two schools in Ramallah governorate refused to participate in the study and were replaced by schools with similar characteristics. Of the 2170 students invited, 2032 (93.6\%) participated in the study. Only students aged 13-15 years were included in this paper, so the final sample consisted of 1942 students (95.6\% of those participating) in this age range. In total, 1863 (95.9\%) parents completed the questionnaires. No significant differences were found between responding and non-responding parents $(n=79)$ in terms of standard of living, residence (urban versus rural) or students' age or sex. However, $2.0 \%$ of parents' questionnaires were missing in Ramallah versus 5.9\% in Hebron ( $P$ $<0.05$ ).

\section{Background characteristics}

Table 1 shows that slightly more of the students were from Hebron, with a higher proportion of girls than boys in both governorates. More students resided in urban areas in Hebron than Ramallah. However, many sociodemographic indicators were better in Ramallah than Hebron: families were smaller, and the mean standard of living index was higher.
The prevalence of underweight was 9.4\% and $12.9 \%$ among boys and $3.8 \%$ and $6.0 \%$ among girls in Ramallah and Hebron respectively. The corresponding figures for stunting were $9.2 \%$ and $9.4 \%$ for boys versus $5.8 \%$ and $4.2 \%$ for girls in Ramallah and Hebron respectively (data not shown).

Table 2 shows that scores for consumption of iron-rich foods were higher in Ramallah than Hebron. Scores were significantly higher for boys than girls for all food types in Ramallah and for legumes in Hebron. The tea consumption scores were higher in Hebron than Ramallah and higher in boys than girls in both governorates.

\section{Haemoglobin levels \& prevalence of anaemia}

Figure 1 shows the distribution of $\mathrm{Hb}$ levels by governorate and sex. For boys, the curve was shifted towards lower values in Hebron. Mean $\mathrm{Hb}$ level was $14.4 \mathrm{~g} / \mathrm{dL}$ in Ramallah and $13.3 \mathrm{~g} / \mathrm{dL}$ in Hebron. For girls, the curves were similar with similar mean $\mathrm{Hb}$ levels in both areas $(13.9 \mathrm{~g} / \mathrm{dL}$ in Ramallah and $13.7 \mathrm{~g} / \mathrm{dL}$ in Hebron).

The prevalence of anaemia in boys was significantly higher in Hebron than Ramallah $(22.5 \%$ versus $6.0 \%$ respectively) $(P<0.0001)$, while the rates for girls were similar in the 2 areas ( $9.3 \%$ and $9.2 \%$ respectively). No cases of severe anaemia were detected and most of the cases of anaemia (90.8\%) were mild. There were large differences between schools in the prevalence of anaemia. In some schools the prevalence was as high as $42 \%$, while in others there were no anaemic students (data not shown).

\section{Anaemia \& sociodemographic characteristics}

Table 3 shows that in Ramallah there were no significant associations for boys between the prevalence of anaemia and sociodemographic characteristics. In Hebron, however, the prevalence of anaemia was high among 13-year-old 


\begin{tabular}{|c|c|c|c|c|}
\hline \multirow[t]{2}{*}{ Variable } & \multicolumn{2}{|c|}{ Ramallah $(n=937)$} & \multicolumn{2}{|c|}{ Hebron $(n=1005)$} \\
\hline & No. & $\%$ & No. & $\%$ \\
\hline \multicolumn{5}{|l|}{ Sex } \\
\hline Boys & 437 & 46.6 & 457 & 45.5 \\
\hline Girls & 500 & 53.4 & 548 & 54.5 \\
\hline \multicolumn{5}{|l|}{ Residence } \\
\hline Urban & 374 & 41.0 & 661 & $67.7^{*}$ \\
\hline Rural & 538 & 59.0 & 315 & 32.3 \\
\hline \multicolumn{5}{|l|}{ Age (years) } \\
\hline 13.0-13.9 & 388 & 41.4 & 330 & 32.8 \\
\hline $14.0-14.9$ & 416 & 44.4 & 483 & 48.1 \\
\hline $15.0-16.0$ & 133 & 14.2 & 192 & 19.1 \\
\hline \multicolumn{5}{|l|}{ Mother's education } \\
\hline Less than secondary school & 663 & 72.6 & 728 & 77.3 \\
\hline Secondary school & 125 & 13.7 & 132 & 14.0 \\
\hline College or university & 125 & 13.7 & 82 & 8.7 \\
\hline \multicolumn{5}{|l|}{ Father's education } \\
\hline Less than secondary school & 558 & 61.3 & 623 & 66.3 \\
\hline Secondary school & 152 & 16.7 & 144 & 15.3 \\
\hline College or university & 200 & 22.0 & 173 & 18.4 \\
\hline \multicolumn{5}{|l|}{ Family size (no. of persons) } \\
\hline $1-6$ & 242 & 27.8 & 117 & $12.4^{* * *}$ \\
\hline $7-8$ & 301 & 34.6 & 355 & 37.7 \\
\hline$<8$ & 327 & 37.6 & 471 & 49.9 \\
\hline Mean (SD) & \multicolumn{2}{|c|}{$8.1(2.5)$} & \multicolumn{2}{|c|}{$8.9(2.5)^{* *}$} \\
\hline \multicolumn{5}{|l|}{ Household standard of living ${ }^{a}$} \\
\hline Low $(0-6)$ & 156 & 18.2 & 291 & $29.5^{* *}$ \\
\hline Medium (7-10) & 419 & 49.0 & 517 & 52.4 \\
\hline High (11-16) & 281 & 32.8 & 179 & 18.1 \\
\hline Mean (SD) & \multicolumn{2}{|c|}{$9.2(2.9)$} & \multicolumn{2}{|c|}{$8.0(2.8)^{* *}$} \\
\hline
\end{tabular}

${ }^{a}$ Household standard of living score based on the possession of 16 household amenities; each item given a value of 1.

The chi-squared test was used to compare differences between governorates for categorical variables and t-test was used to compare means. ${ }^{*} P<0.05 ;{ }^{* *} P<0.01 ;{ }^{* * *} P<0.001$

$S D=$ standard deviation

boys $(28.9 \%)(P=0.036)$ and among $\quad(28.7 \%)(P=0.012)$. A trend of increas- family size was noted. In Ramallah, anaethose with a low standard of living ing rates of anaemia with increasing mia in girls was significantly associated

\begin{tabular}{|c|c|c|c|c|}
\hline \multirow[t]{3}{*}{ Food consumption } & \multicolumn{2}{|c|}{ Ramallah } & \multicolumn{2}{|c|}{ Hebron } \\
\hline & Boys & Girls & Boys & Girls \\
\hline & Mean score (SE) & Mean score (SE) & Mean score (SE) & Mean score (SE) \\
\hline Animal foods & $3.0(0.1)$ & $2.2(0.1)^{* * *}$ & $2.2(0.1)$ & $1.9(0.1)$ \\
\hline Legumes & $2.3(0.1)$ & $1.9(0.1)^{* *}$ & $2.0(0.1)$ & $1.6(0.1)^{* *}$ \\
\hline Green leafy vegetables & $1.2(0.1)$ & $0.9(0.1)^{* *}$ & $1.0(0.1)$ & $0.9(0.1)$ \\
\hline Taboun bread & $1.2(0.1)$ & $0.9(0.1)^{*}$ & $0.8(0.1)$ & $0.9(0.1)$ \\
\hline Tea & $16.0(0.8)$ & $12.5(0.7)^{* *}$ & $19.2(0.9)$ & $16.5(1.0)$ \\
\hline
\end{tabular}

${ }^{*} P<0.05{ }^{* *} P<0.01{ }^{* * *} P<0.001$.

$S E=$ standard error. 


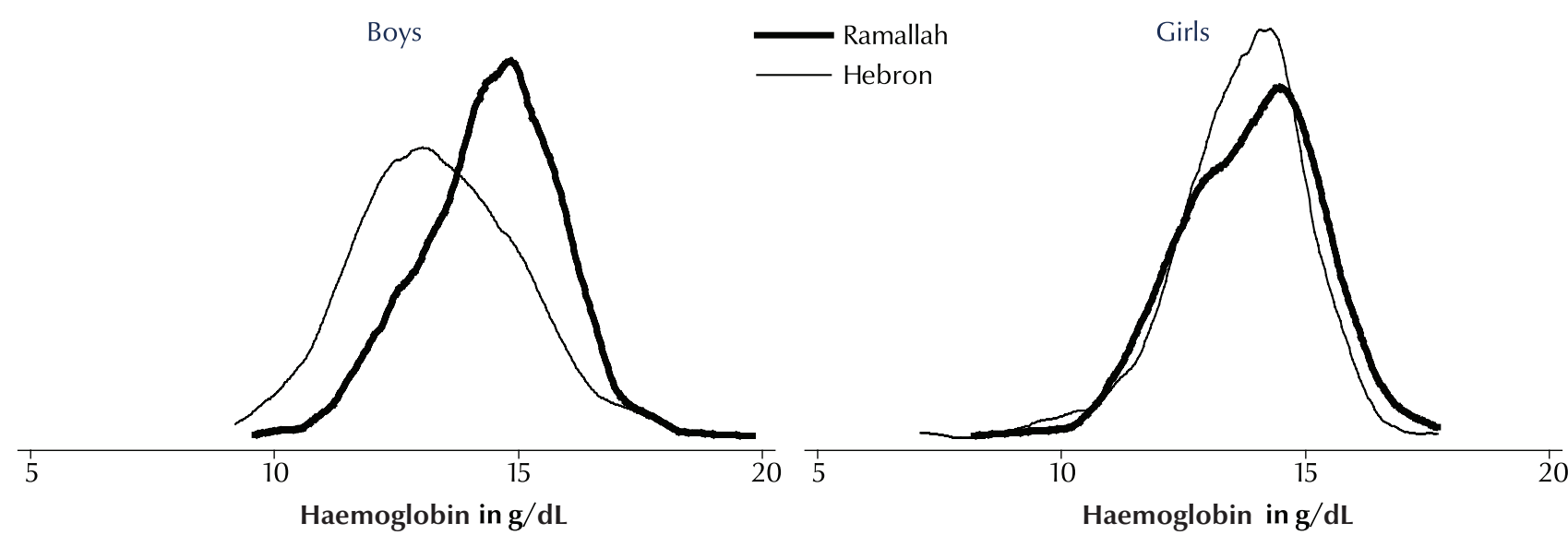

Figure 1 Distribution of haemoglobin levels of Palestinian adolescents in Ramallah and Hebron governorates by governorate and sex

with a high level of father's education $(P=0.010)$, whereas in Hebron no significant associations were found between anaemia and the sociodemographic characteristics of girls.

\section{Anaemia \& anthropometric characteristics}

The relationship between anaemia and stunting and underweight was significant, especially for boys. A much higher proportion of anaemic boys were stunted than were non-anaemic boys $(17.6 \%$ versus $7.6 \%)(P=0.005)$. Similarly, $20.3 \%$ of anaemic boys were underweight versus only $9.8 \%$ of the non-anaemic boys $(P=0.002)$ (Table 4).

\section{Regression analysis}

The regression model results are shown in Table 5. For boys, model 1 showed that the prevalence of anaemia was $14.4 \%$ (constant term) if all the cofactors were at the reference category. Boys from Hebron had 14.7 percentage points (pp) higher prevalence of anaemia compared with their counterparts in Ramallah $(P<0.001)$. By age group 14-year-old boys had a $8.6 \mathrm{pp}$ lower risk of anaemia compared with 13-yearold boys $(P<0.05)$. Boys from high standard of living households had $9 \mathrm{pp}$ lower prevalence of anaemia compared with those from low standard of living households $(P<0.05)$. In model 2, boys from Hebron had 13.8 pp increased risk of anaemia compared with their counterparts in Ramallah (data not shown). None of the consumption scores for iron-rich food showed any significant association with the prevalence of anaemia, but there was a tendency for a lower prevalence of anaemia among boys who ate more animal foods ( $2.1 \mathrm{pp}$ decrease in anaemia per unit animal food score). Separate models for each governorate did not show any significant associations between dietary factors and anaemia (data not shown).

For girls, the expected prevalence at reference categories for all the co-factors in model 1 was only 1.4\% (constant term). Those whose fathers had medium or high educational level had $5.9 \mathrm{pp}$ and $6.7 \mathrm{pp}$ added risk of anaemia compared with those whose fathers had low education $(P<0.05)$. Medium and high levels of mother's education showed a tendency to decrease the risk of anaemia compared with low mother's education but not significantly so. Again, none of the iron-rich food consumption scores in model 2 showed any significant effect on the prevalence of anaemia, but there was a tendency for a lower prevalence of anaemia among girls who ate more legumes ( $1.1 \mathrm{pp}$ decrease in anaemia per unit legume score).
No significant interactions between the independent variables were detected. All continuous covariates showed linear effects, and no observations with unduly high influence were found. However, some negative results were predicted (7.3\% for boys and $0.2 \%$ for girls in model 1).

\section{Discussion}

This study showed that the rate of anaemia among boys in Hebron (22.5\%) was significantly higher than among boys in Ramallah (6.0\%). This value was also higher than among girls in both Ramallah and Hebron (around 9\%), despite the fact that most of the girls had already reached puberty.

Studies on anaemia among Palestinian adolescents are scarce. Two reports showed that the prevalence of irondeficiency anaemia was $12.7 \%$ among school-age children (aged 6-18 years) in Salfeet governorate [11] and 5.0\% among secondary-school students in Jenin governorate. Both these studies reported that a higher proportion of girls were anaemic than boys [12]. A study in Gaza Strip in 2002 on adolescents aged $12-15$ years reported that the prevalence of anaemia was $47.9 \%$ and $51.3 \%$ among boys and girls respectively [13]. This was much higher than 


\begin{tabular}{|c|c|c|c|c|c|c|c|c|c|c|c|c|}
\hline \multirow[t]{3}{*}{ Variable } & \multicolumn{6}{|c|}{ Ramallah } & \multicolumn{6}{|c|}{ Hebron } \\
\hline & \multicolumn{3}{|c|}{ Boys $(n=437)$} & \multicolumn{3}{|c|}{ Girls $(n=500)$} & \multicolumn{3}{|c|}{ Boys $(n=457)$} & \multicolumn{3}{|c|}{ Girls $(n=548)$} \\
\hline & No. & $\%$ & $P$-value ${ }^{a}$ & No. & $\%$ & $P$-value ${ }^{a}$ & No. & $\%$ & $P$-value ${ }^{a}$ & No. & $\%$ & $P$-value ${ }^{\text {a }}$ \\
\hline Total & 437 & 6.0 & - & 500 & 9.2 & $0.127^{b}$ & 457 & 22.5 & - & 548 & 9.3 & $<0.001^{\mathrm{b}}$ \\
\hline \multicolumn{13}{|l|}{ Residence } \\
\hline Urban & 197 & 5.1 & 0.485 & 177 & 10.2 & 0.646 & 308 & 19.8 & 0.102 & 353 & 8.8 & 0.682 \\
\hline Rural & 228 & 7.0 & & 310 & 8.7 & & 133 & 28.6 & & 182 & 9.9 & \\
\hline \multicolumn{13}{|l|}{ Age (years) } \\
\hline 13.0-13.9 & 180 & 5.6 & & 208 & 8.2 & & 180 & 28.9 & & 150 & 8.0 & \\
\hline $14.0-14.9$ & 192 & 4.7 & 0.247 & 224 & 9.8 & 0.802 & 210 & 17.6 & 0.036 & 273 & 9.2 & 0.608 \\
\hline 15.0-16.0 & 65 & 10.8 & & 68 & 10.3 & & 67 & 20.9 & & 125 & 11.2 & \\
\hline \multicolumn{13}{|c|}{ Mother's education } \\
\hline Low & 307 & 6.8 & & 356 & 9.8 & & 316 & 25.6 & & 412 & 9.5 & \\
\hline Medium & 56 & 3.6 & 0.432 & 69 & 4.4 & 0.296 & 67 & 16.4 & 0.231 & 65 & 10.8 & 0.916 \\
\hline High & 54 & 3.7 & & 71 & 11.3 & & 38 & 15.8 & & 44 & 9.1 & \\
\hline \multicolumn{13}{|c|}{ Father's education } \\
\hline Low & 270 & 7.0 & & 288 & 6.6 & & 277 & 24.6 & & 346 & 8.4 & \\
\hline Medium & 64 & 6.3 & 0.326 & 88 & 10.2 & $0.010^{c}$ & 59 & 27.1 & 0.274 & 85 & 11.8 & 0.443 \\
\hline High & 84 & 2.4 & & 116 & 13.8 & & 84 & 16.7 & & 89 & 11.2 & \\
\hline \multicolumn{13}{|c|}{ Family size (no. of persons) } \\
\hline $1-6$ & 129 & 3.9 & & 113 & 6.2 & & 58 & 13.8 & & 59 & 8.5 & \\
\hline $7-8$ & 142 & 7.8 & 0.363 & 159 & 9.4 & 0.252 & 166 & 22.3 & $0.193^{c}$ & 189 & 9.0 & 0.839 \\
\hline 8 & 111 & 8.1 & & 216 & 11.1 & & 195 & 27.2 & & 276 & 10.1 & \\
\hline \multicolumn{13}{|c|}{ Household standard of living ${ }^{d}$} \\
\hline Low & 56 & 8.9 & & 100 & 9.0 & & 115 & 28.7 & & 176 & 8.0 & \\
\hline Medium & 202 & 7.9 & 0.182 & 217 & 10.1 & 0.866 & 231 & 22.9 & $0.012^{\mathrm{e}}$ & 286 & 10.8 & 0.308 \\
\hline High & 147 & 2.7 & & 134 & 9.0 & & 103 & 13.6 & & 76 & 6.6 & \\
\hline \multicolumn{13}{|c|}{ Onset of puberty } \\
\hline No & 74 & 5.4 & 0.800 & 100 & 8.0 & 0.752 & 92 & 27.2 & 0.061 & 84 & 7.1 & 0.442 \\
\hline Yes & 363 & 6.1 & & 391 & 9.2 & & 364 & 21.4 & & 464 & 9.7 & \\
\hline
\end{tabular}

a for differences between sociodemographic characteristics using the chi-squared test.

${ }^{b} \mathrm{P}$ for differences between boys and girls in the same governorate using the chi-square test.

$c P$ for trend $=0.05$.

${ }^{d}$ Household standard of living score based on the possession of 16 household amenities; each item given a value of 1 .

epfor trend $<0.05$.

\begin{tabular}{|c|c|c|c|}
\hline $\begin{array}{l}\text { Table } 4 \text { Pre } \\
\text { adolescen }\end{array}$ & $\begin{array}{l}\text { aemia in stunted and un } \\
\text { lah and Hebron governo }\end{array}$ & $\begin{array}{l}\text { eight Palest } \\
(n=1942)\end{array}$ & \\
\hline Variable & $\%$ of student & & $P$-value \\
\hline & Normal haemoglobin $^{a}$ & Anaemia $^{a}$ & \\
\hline Stunting & & & \\
\hline All & 6.1 & 11.8 & 0.012 \\
\hline Boys & 7.6 & 17.6 & 0.005 \\
\hline Girls & 4.9 & 2.7 & 0.354 \\
\hline Underwei & & & \\
\hline All & 7.4 & 13.6 & 0.005 \\
\hline Boys & 9.8 & 20.3 & 0.002 \\
\hline Girls & 5.5 & 3.4 & 0.388 \\
\hline
\end{tabular}

${ }^{a}$ Weighted estimates. the prevalence of anaemia for boys and girls in our sample. These differences might be explained by a worse economic situation [14], lower nutritional status [15], lower intake of animal foods [16] and a higher rate of parasitic infestations [17] in Gaza.

The prevalence of anaemia among adolescents in other countries in the Eastern Mediterranean region is reported to range from $30 \%$ to $55 \%$, with the mild forms of anaemia predominating [18]. These figures are higher than 


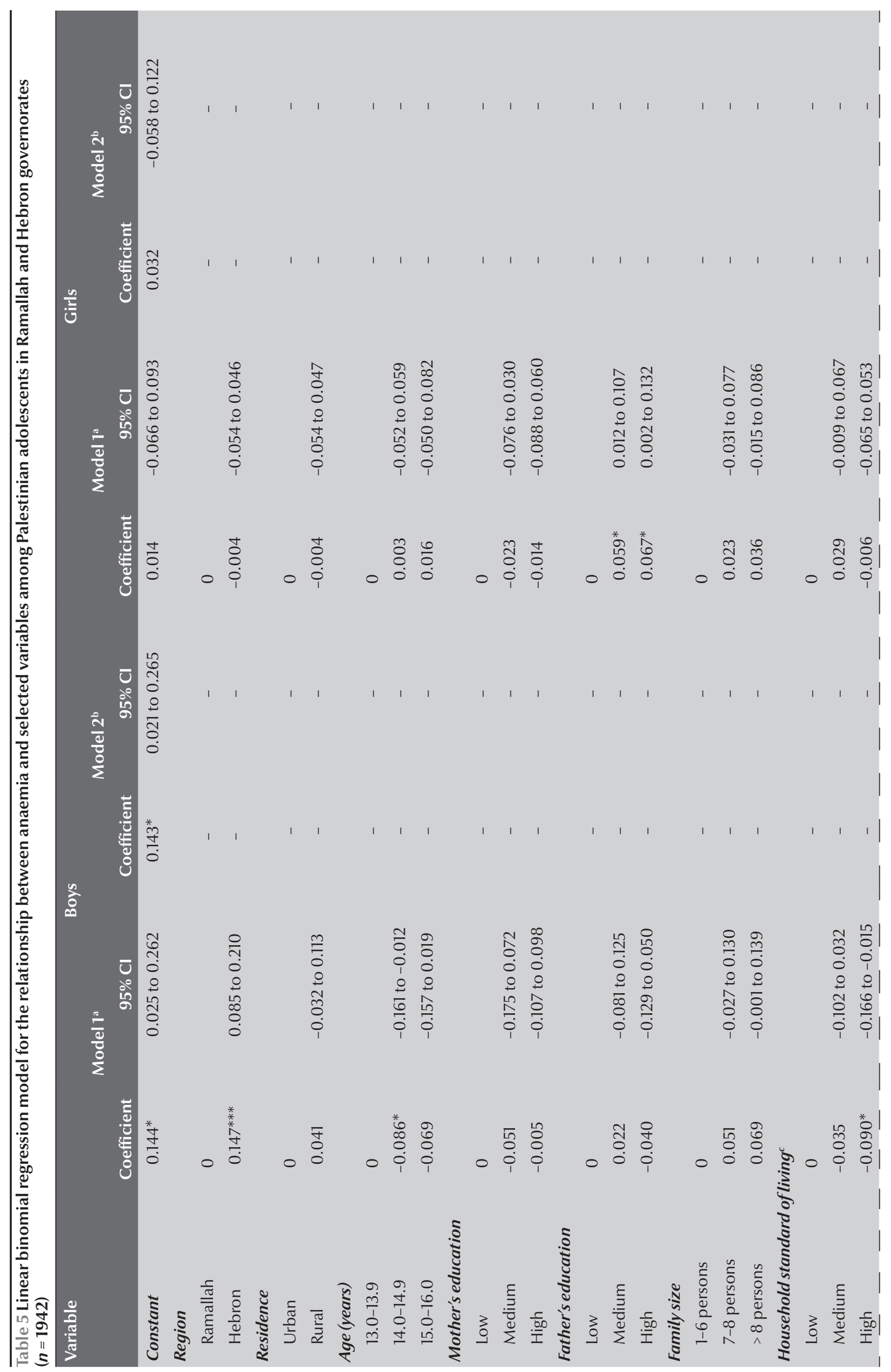




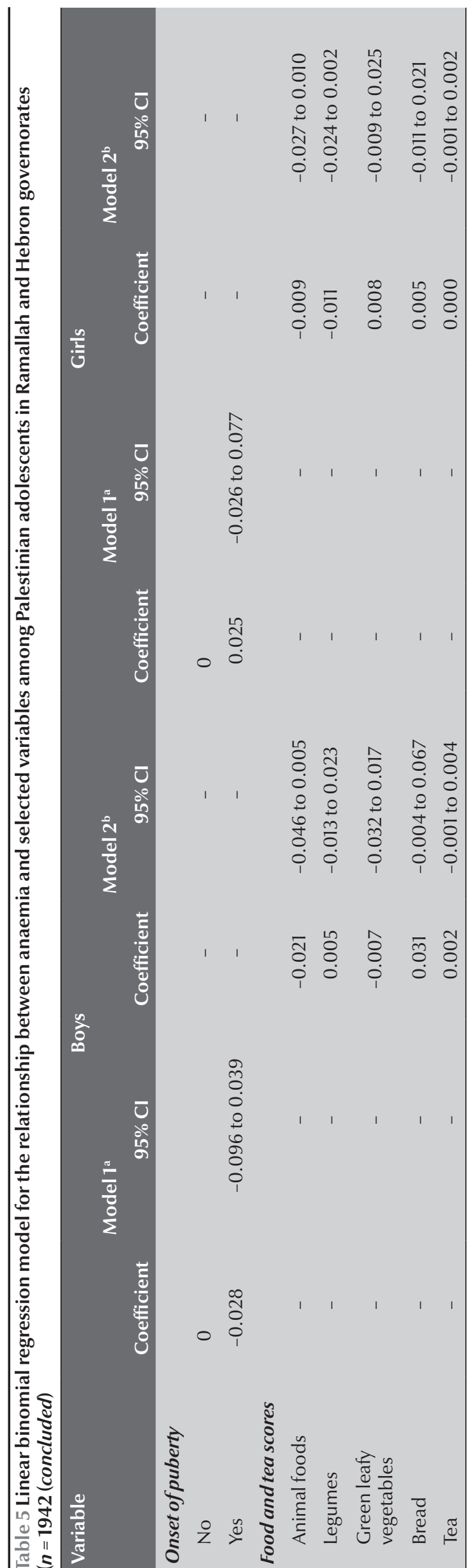

the figures in our study, especially for Ramallah governorate. However, some studies reported figures close to our estimates, for example in Egypt [19], Saudi Arabia [20] and Iraq [21]. In other studies, the prevalence of anaemia has been shown to decline sharply after the age of 16 years among adolescent boys, whereas the rate starts to increase after the age of 18 years among girls [21,22].

The higher prevalence of anaemia among boys in Hebron is interesting. Hebron is more disadvantaged than Ramallah in terms of family size and standard of living [23]. Moreover, boys from Hebron were found to be more stunted and more underweight than either boys in Ramallah or girls in Hebron and Ramallah. Regional and sex differences might stem from a variety of sources apart from sociodemographic and nutritional factors, such as hereditary factors, parasitic infestations or environmental pollutants that were not measured in our study. Palestinian boys spend more time outdoors which might predispose them to certain infections that can lead to both anaemia and stunting. Iron deficiency has been associated with high blood lead levels in many studies $[5,24]$. One study has confirmed high lead levels in children in the West Bank [25].

Low intake of bioavailable iron from the diet is one of the main causes of anaemia [4]. Our results did not show any associations between the level of consumption of selected iron-rich foods and anaemia. This could be due to the fact that we only estimated frequency intake without portion sizes. Frequency of tea intake was not associated with increased risk of anaemia in our study. A similar lack of association was found in another study among Palestinian children [7].

Low intake of iron-rich food is a risk factor for poor physical growth [3]. Anaemia was significantly associated with stunting and underweight in our sample, especially among boys. 
We used a linear binomial regression model. The advantages of this model are that it is easy to interpret and it gives the prevalence of anaemia for any covariate combination. The downside of the model is that it is not well known and it might predict values outside 0 and 1 , as we found in our study.

The study had several limitations. First, due to cost considerations and to the concern over high refusal rates, $\mathrm{Hb}$ was only measured using capillary finger-prick samples. We did not measure serum iron and ferritin, nor could we do Hb electrophoresis. But, as the prevalence of thalassaemia trait in Palestine is low (3.5\%) [26], we did not expect that this would contribute substantially to the explanation of anaemia in our sample. We did not have any information on infections or lead levels in our data. Moreover, our dietary data were based on a self-reported food frequency questionnaire and portion sizes were not given. The study was done in 2 governorates in the West Bank and the reported prevalence cannot be generalized to the rest of the West Bank. The strengths of the study include its relatively large sample size, single-stage cluster sampling method, the urban/rural distribution and the high response rate. Although the questionnaire was not validated, it was tested for reliability and the 1-week test-retest reliability of relevant questions was moderate to high.

The findings of this study point to a high prevalence of anaemia among boys in Hebron. Poverty, poor intake of iron-rich food, infections or lead toxicity might be associated factors. Further studies are needed to identify causes of anaemia among boys in Hebron in order to plan proper interventions.

\section{Acknowledgements}

This study is a collaboration between Birzeit University and the University of Oslo and was supported by a grant from the Norwegian Programme for Development, Research and Education (NUFU) PRO X1 $50 / 2002$.

We would like to thank participating schools and the Palestinian Ministry of Education and Higher Education and the UNRWA Office of Education for facilitating the fieldwork.

We are grateful to Alpha International for Research, Polling and Informatics for conducting fieldwork and for statistical support.

\section{References}

1. Iron deficiency anaemia: assessment, prevention and control. A guide for programme managers. Geneva, World Health Organization, 2001 (WHO/NHD/01.3).

2. Assessing the iron status of populations: report of a Joint World Health Organization/Centers for Disease Control and Prevention. Geneva, World Health Organization and Centers for Disease Control and Prevention, 2005.

3. Black RE et al.; Maternal and Child Undernutrition Study Group. Maternal and child undernutrition: global and regional exposures and health consequences. Lancet, 2008, 371:243-260.

4. López MA, Martos FC. Iron availability: An updated review. International Journal of Food Sciences and Nutrition, 2004, 55:597-606.

5. Choi JW, Kim SK. Relationships of lead, copper, zinc, and cadmium levels versus hematopoiesis and iron parameters in healthy adolescents. Annals of Clinical and Laboratory Science, 2005, 35:428-434.

6. Massa'd S. Prevalence of anaemia and associated factors in a rural Palestinian population [Masters thesis]. Ramallah, Palestine, Institute of Community and Public Health, Birzeit University, 2001.

7. Halileh S, Gordon NH. Determinants of anemia in pre-school children in the occupied Palestinian territory. Journal of Tropical Pediatrics, 2006, 52:12-18.

8. Population, housing and establishment census 2007. Final results in the West Bank-summary (Population and housing). Ramallah, Palestine, Palestinian Central Bureau of Statistics, 2008.

9. Dissemination and analysis of census findings. Analytical report series (04). Characteristics of urban and rural areas in the Palestinian Territory. Ramallah, Palestine, Palestinian Central Bureau of Statistics, 2003.

10. Kuczmarski RJ et al. 2000 CDC Growth Charts for the United States: methods and development. Vital and Health Statistics 11, 2002, (246):1-190.
11. Odeh M. Prevalence of iron deficiency anemia among school children in Salfeet district [Masters thesis]. Nablus, Palestine, Faculty of Graduate Studies, An-Najah University, 2006.

12. Krewish I. Prevalence of thalasemia trait, iron deficiency anemia and level of thalasemia awareness among secondary school students in Jenin District [Masters thesis]. Nablus, Palestine, Faculty of Graduate Studies, an-Najah University, 2003.

13. Abudayya A et al. Overweight, stunting and anemia are public health problems among low socioeconomic groups in school adolescents (12-15 years) in the North Gaza Strip. Nutrition Research (New York, N.Y.), 2007, 2007:762-771.

14. Two years after London: restarting Palestinian economic recovery. Economic monitoring report to the Ad Hoc Liaison committee. Washington DC, World Bank, 2007

15. Nutritional assessment of the West Bank and the Gaza Strip. Jerusalem, Al Quds University/Johns Hopkins University/ CARE, 2003.

16. Al Sabbah $\mathrm{H}$ et al. Food habits and physical activity patterns among Palestinian adolescents: findings from the national study of Palestinian schoolchildren (HBSC-WBG2004). Public Health Nutrition, 2007, 10:739-746.

17. Astal Z. Epidemiological survey of the prevalence of parasites among children in Khan Younis governorate, Palestine. Parasitology Research, 2004, 94:449-451.

18. Bagchi K. Iron deficiency anaemia-an old enemy. Eastern Mediterranean Health Journal, 2004, 10:754-760.

19. Barduagni $P$ et al. Anaemia among schoolchildren in Qena Governorate, Upper Egypt. Eastern Mediterranean Health Journal, 2004, 10:916-920.

20. Abou-Zeid AH et al. Anemia and nutritional status of schoolchildren living at Saudi high altitude area. Saudi Medical Journal, 2006, 27:862-869.

21. Al-Sharbatti SS, Al-Ward NJ, Al-Timimi DJ. Anemia among adolescents. Saudi Medical Journal, 2003, 24:189-194. 
22. El-Sahn F et al. Anaemia among Egyptian adolescents: prevalence and determinants. Eastern Mediterranean Health Journal, 2000, 6:1017-1025.

23. Taraki L, Giacaman R. Modernity aborted and reborn. Ways of being urban in Palestine. In: Taraki L, ed. Living Palestine: family survival, resistance and mobility under occupation, 1st ed. New York, Syracuse University Press, 2006:1-50.

24. Muwakkit S et al. Iron deficiency in Young Lebanese children: association with elevated blood lead levels. Journal of Pediatric Hematology/Oncology, 2008, 30:382-386.
25. Zyoud A. Blood lead levels among school children in Jenin district [Masters thesis]. Nablus, Palestine, Faculty of Graduate Studies, An-Najah National University, 2001.

26. Darwish HM, El-Khatib FF, Ayesh S. Spectrum of betaglobin gene mutations among thalassemia patients in the West Bank region of Palestine. Hemoglobin, 2005, 29:119-132.

\section{Adolescent health}

There are sound public health, economic and human rights reasons for investing in the health and development of adolescents. Greater investment in adolescent health would help prevent the estimated 1.4 million deaths that occur each year among 10-19 year olds due to road traffic accidents, complications during pregnancy and child birth, suicide, violence, and HIV/AIDS. It would also improve the health and well-being of many millions of adolescents who experience health problems such as depression or anaemia; and promote the adoption of behaviours that help prevent health problems later in life, such as cardiovascular diseases and lung cancer resulting from physical inactivity and tobacco use initiated during adolescence. Finally, investing in adolescent health can prevent problems in the next generation, such as prematurity and low-birthweight in infants born to very young mothers. There is growing recognition of the economic benefits of investing in the healthy development of adolescents, and the economic costs of not doing so. Almost all Member States are signatories to the UN Convention on the Rights of the Child, which clearly states that adolescents have the right to obtain the health information and services they need to survive, grow and develop to their full potential.

Source: Child and adolescent health and development: progress report 2009: highlights. Geneva, World Health Organization, 2010 